\title{
Tratamento cirúrgico de cisto radicular em maxila: relato de caso
}

\author{
Surgical treatment of radicular cisto maxila: case report \\ Tratamiento quirúrgico de quiste radicular en maxilar: reporte de caso \\ Dannilo Wiklymber Roldao MENDONÇA ${ }^{1}$ \\ Helinaldo Corrêa da CONCEIÇÃ̃ ${ }^{1}$ \\ Valber Barbosa MARTINS ${ }^{2}$ \\ Karoline Araújo LIMA ${ }^{3}$
}

\author{
${ }^{1}$ Acadêmico do Curso de Graduação em Odontologia, Escola Superior de Ciências da Saúde, \\ Universidade do Estado do Amazonas, UEA 69065-001 Manaus-AM, Brasil \\ ${ }^{2}$ Professor da Escola Superior de Ciências da Saúde, Universidade do Estado do Amazonas, UEA \\ 69065-001 Manaus-AM, Brasil, \\ Especialista e Mestre em Cirurgia e Traumatologia Bucomaxilofacial. \\ ${ }^{3}$ Graduação em Odontologia e Residência em Cirurgia e Traumatologia Buco-Maxilo-Facial pela
}

Universidade do Estado do Amazonas-UEA 69065-001 Manaus-AM, Brasil

\begin{abstract}
Resumo
O cisto radicular é uma lesão de natureza inflamatória, que possui prevalência mais comum de todos os cistos odontogênicos que afetam o complexo maxilomandibular, correspondendo a uma frequência de 54\% das radiotransparências periapicais, verificadas em radiografias convencionais. Clinicamente, a lesão é assintomática, geralmente localizada na porção anterior da maxila, associada à tumefação, mobilidade e, por vezes, deslocamento dentário. No presente estudo, é relatado um caso de uma paciente de 28 anos de idade que possuía um cisto periapical na região anterior da maxila, associado às raízes dos elementos dentais 11, 12 e 13 e que se apresentava em contato com estruturas anatômicas importantes dessa região, como o seio maxilar e a fossa nasal. O tratamento proposto então foi a enucleação e curetagem do mesmo em centro cirúrgico, sob anestesia geral. Concluiu-se que a enucleação, como terapêutica de primeira escolha, em conformidade com diversos autores, é uma boa alternativa para o tratamento destas lesões.

Descritores: Cisto Radicular; Cistos Odontogênicos; Cirurgia Bucal.
\end{abstract}

\begin{abstract}
The radicular cyst is an inflammatory nature lesion that has most common prevalence of all odontogenic cyst affecting the maxillo-mandibular complex, corresponding to a frequency 54\% of periapical radiotransparências, recorded on conventional radiographs. Clinically, the lesions are asymptomatic, generally located in the anterior part of the maxilla, associated with swelling, mobility and sometimes tooth displacement. This study reports a case of a 28 year old patient who had an average periapical cyst in the anterior maxilla, associated with the roots of the dental elements 11,12 and 13 and who had contact with important anatomical structures that region, such as the maxillary sinus and nasal cavity. The proposed treatment was then enucleation and curettage of the same in the operating room under general anesthesia. It was concluded that enucleation, as therapy of choice, according to several authors, it is a good alternative for the treatment of these lesions.
\end{abstract}

Descriptors: Radicular Cyst; Odontogenic Cysts; Surgery, Oral.

\section{Resumen}

El quiste radicular es una lesión de naturaleza inflamatoria, que tiene una prevalencia más común de todos los quistes odontogénicos que afectan al complejo maxilomandibular, correspondiendo a una frecuencia del 54\% de las radiotransparencias periapicales, verificadas en radiografías convencionales. Clínicamente, la lesión es asintomática, generalmente localizada en la porción anterior de la mandíbula, asociada a la tumefacción, la movilidad y, a veces, el desplazamiento dental. En el presente estudio, se relata un caso de una paciente de 28 años de edad que poseía un quiste periapical en la región anterior de la mandíbula, asociado a las raíces de los elementos dentales 11,12 y 13 y que se presentaba en contacto con estructuras anatómicas importantes de esa región Como el seno maxilar y la fosa nasal. El tratamiento propuesto entonces fue la enucleación y curetaje del mismo en centro quirúrgico, bajo anestesia general. Se concluyó que la enucleación, como terapia de primera elección, de acuerdo con diversos autores, es una buena alternativa para el tratamiento de estas lesiones.

Descriptores: Quiste Radicular; Quistes Odontogénicos; Cirugía Bucal.

\section{INTRODUÇÃO}

Os cistos radiculares, também conhecidos como cistos periapicais, são cistos inflamatórios localizados na região perirradicular de um dente desvitalizado. Por definição, estes são caracterizados pela formação de uma cavidade patológica, revestida por epitélio e uma cápsula constituída por tecido conjuntivo, contendo em seu interior um material líquido ou semissólido ${ }^{1,2}$. É precedido pelo granuloma periapical, com epitélio preexistente, o qual constitui um foco de tecido de granulação, cronicamente inflamado, intraósseo, no ápice de dentes sem vitalidade ${ }^{3,4}$.
Os cistos representam o último passo na progressão dos eventos inflamatórios, secundários à necrose pulpar de uma unidade dentária. A fonte epitelial é comumente os restos epiteliais de Malassez, derivados da desorganização apoptótica da bainha de Hertwig, mas também pode ser relacionada ao epitélio crevicular, ao revestimento sinusal ou ao revestimento epitelial dos trajetos fistulosos ${ }^{4}$.

Dentre as lesões císticas nos maxilares, são os mais comuns envolvendo de $52 \%$ a $68 \%$ de todos os cistos da cavidade bucal. Ocorrem com maior frequência em homens, 
entre 20 a 40 anos de idade ${ }^{5}$, e são mais prevalentes nos brancos do que em negros ${ }^{6,7}$. A maior parte dos cistos radiculares não apresenta sintomatologia, mas pode haver dor ou sensibilidade se ocorrer exacerbação inflamatória aguda. Em lesões extensas, pode haver tumefação, mobilidade e deslocamento dentário, e o dente de origem não responde ao teste pulpar térmico ou elétrico ${ }^{8}$.

Radiograficamente, os cistos radiculares são idênticos ao granuloma periapical. Apresentam uma imagem radiolúcida, unilocular, arredondada, associada ao ápice radicular de um dente desvitalizado e com rompimento da lâmina dura no nível apical. A lesão ainda é delimitada por uma linha de esclerose óssea, marcadamente radiopaca, que não deve ser confundida com a membrana cística fibrosa, que está englobada na área radiolúcida ${ }^{9}$.

Histologicamente, a lesão cística exibe uma cápsula de tecido conjuntivo fibroso, revestido por epitélio escamoso estratificado, com lúmen contendo em seu interior líquido e restos celulares.

Existem diferentes formas de tratamento para os cistos radiculares, como: tratamentos conservadores (através do tratamento endodôntico do dente desvitalizado, com ou sem apicectomia), tratamentos cirúrgicos como a extração da unidade dentária (seguida de curetagem periapical), marsupialização, descompressão ou ainda a enucleação cística $^{8,9}$.

A divulgação deste caso clínico é de grande importância no meio científico e social, servindo como base para direcionar o tratamento em situações semelhantes.

Desta forma, o objetivo geral do presente trabalho é relatar um caso clínico de sucesso, relacionado ao tratamento cirúrgico de um cisto radicular em maxila, onde foi realizada sua enucleação como tratamento definitivo. Como objetivos específicos busca realizar uma revisão de literatura sobre os métodos de diagnóstico e tratamento do cisto radicular, bem como enfatizar características clínicas, epidemiológicas, radiográficas e histopatológicas do cisto radicular, bem como relatar os resultados obtidos com o tratamento e a proservação do presente caso.

\section{REVISÃO DA LITERATURA}

Cisto pode ser definido como uma cavidade patológica, revestida por epitélio de origem odontogênica, usualmente contendo, em seu interior, material fluído ou semifluído $^{10}$. O cisto radicular é um cisto odontogênico inflamatório decorrente de lesões pulpares causadas por cárie ou traumas ${ }^{7}$.

De acordo com a atual classificação internacional da Organização Mundial de Saúde $(\mathrm{OMS})^{11}$, os cistos odontogênicos são classificados em dois grupos principais, que refletem sua patogênese. $\mathrm{O}$ primeiro grupo inclui cistos radiculares, sendo reconhecida sua origem inflamatória como consequência de cáries avançadas e necrose pulpar. $\mathrm{O}$ segundo grupo inclui lesões conhecidas como cistos de desenvolvimento.

Existem, fundamentalmente, três teorias para a formação dos cistos radiculares: a teoria nutricional defende que, com o estímulo inflamatório, ocorre desenvolvimento epitelial na região e as células mais centrais, longe da fonte nutricional, sofrem necrose por liquefação, dando origem assim à cavidade cística. A segunda teoria defende que, com o desenvolvimento do abscesso, células epiteliais proliferam, formando cordões que o revestem. Finalmente, de acordo com a terceira teoria, os restos epiteliais de Malassez proliferam, formando cordões que se fusionam dando origem a uma cavidade. Com a descamação de restos celulares, aumenta o conteúdo protéico no interior dessa cavidade, acontecendo, consequentemente, entrada de líquido com intuito de causar a estabilização osmótica, levando, assim, ao desenvolvimento da lesão ${ }^{12}$.

O cisto radicular é a lesão odontogênica inflamatória mais comumente encontrada nos maxilares, tendo sua gênese a partir de um granuloma periapical. $\mathrm{O}$ revestimento epitelial do cisto periapical é decorrente do desenvolvimento das células epiteliais de Malassez, presente no ligamento periodontal, que sofrem apoptose e dão origem à cavidade cística, em resposta à estimulação antigênica contínua proveniente do sistema de canais radiculares, sendo determinante a participação de microrganismos e seus produtos, mantendo o processo inflamatório local ${ }^{3,6,8}$.

A inflamação periapical estimula a secreção de citocinas e fatores de crescimento que induzem a proliferação dos restos epiteliais de Malassez inativos, iniciando um processo de hiperplasia inflamatória periapical $^{13}$.

Os cistos radiculares ocorrem com maior frequência na dentição permanente ${ }^{14,15,16}$, porém, na dentição decídua, deixam de ser diagnosticados, em razão de diagnósticos errôneos e de falta de análise histopatológica das lesões. Um percentual de 4,8\% das lesões císticas em dentes decíduos consiste em cistos radiculares, sendo a maioria deles agregada a molares inferiores ${ }^{7}$

Os cistos radiculares possuem maior incidência em adultos, na faixa etária de 20 a 40 anos, afetando especialmente indivíduos do gênero masculino, e têm como local de maior incidência a região anterior da maxila ${ }^{17}$. Quanto à raça, foi verificada maior prevalência em leucoderma do que em melanodermas ${ }^{6,18}$.

A grande maioria das lesões periapicais é assintomática, a menos que esteja presente uma exacerbada resposta inflamatória, muitas vezes de origem infecciosa. A infecção bacteriana secundária pode causar dor espontânea, exsudação e aumento rápido de volume da cavidade cística, como sinais da resposta inflamatória aguda na parede do cisto $^{4,19}$. Nesses casos, pode ocorrer tumefação, sensibilidade, mobilidade ou deslocamento dental, além da ausência de sensibilidade pulpar ${ }^{20}$.

$\mathrm{O}$ cisto radicular pode chegar a tamanhos consideráveis, ocasionando a expansão da cortical óssea externa e uma tumefação dura e indolor. Com o rompimento desta cortical fina e rarefeita, a tumefação apresenta-se mole à palpação, mas com uma resiliência marcante, sendo designada de consistência cística ou flutuante. Neste estágio, a mucosa bucal que recobre o cisto pode mostrar-se com cor azulada e consistência normais. A invasão de nervos não ocasiona deficiência sensorial ${ }^{4}$.

Há relato na literatura de um cisto radicular raro, onde a lesão apresentava grandes dimensões e envolvia o seio maxilar, estendendo-se até o assoalho da cavidade nasal, do lado direito. A patologia provocou parestesia no lado $\operatorname{afetado}^{20}$.

O cisto periapical representa 7 a $54 \%$ das radiolucências apicais e mostra-se radiograficamente, idêntico ao do granuloma periapical ${ }^{5}$. Os cistos podem desenvolver-se mesmo como radiotransparências periapicais pequenas, e o tamanho radiográfico da lesão não pode ser utilizado para o diagnóstico definitivo. Observa-se perda da lâmina dura ao longo da raiz adjacente, e uma radiotransparência arredondada que circunda o ápice do dente desvitalizado ${ }^{11}$. No entanto, o diagnóstico radiográfico do cisto radicular não pode ser tomado como definitivo, pois sempre terá a possibilidade de diagnóstico de outras 
entidades mais agressivas localizadas no periápice, as quais podem simular periapicopatias verdadeiras ${ }^{4}$.

A radiografia desempenha um papel principal na verificação das regiões do periápice dentário e todo tecido ósseo que o circunda, detectando as lesões que ali possam se localizar, principalmente quando estas estão isentas de sintomatologia clínica. É, portanto um meio de diagnóstico imprescindível, pois, através dela, além de visualizar as lesões existentes, podem-se determinar suas relações, tamanho e possíveis origens. As lesões inflamatórias que envolvem os ápices dos elementos dentários têm a capacidade de promover lise ou destruição do tecido ósseo na região. Esta diminuição da densidade óssea ou esta perda de substância óssea favorece e promove a penetração do feixe de raios $\mathrm{X}$, causando o desenvolvimento de imagens radiolúcidas ${ }^{21}$

A radiografia panorâmica representa uma opção para avaliar as condições periapicais, sendo recomendada como costume na consulta clínica odontológica, preferentemente a partir dos cinco anos de idade do paciente. Este exame tem a capacidade de captar toda a área óssea e dentada que compõe o complexo estomatognático do indivíduo ${ }^{22}$.

Radiograficamente, o diagnóstico diferencial do cisto radicular deve incluir o granuloma periapical ${ }^{3,4,23}$. No diagnóstico realizado através da radiografia é de grande valor a observação do tamanho da área ocupada pela lesão. À medida que aumenta o tamanho da área, a probabilidade de ser um cisto radicular também aumenta. Mas apesar da maioria das lesões menores se traduzirem microscopicamente em granulomas apicais, isto não ocorre constantemente $^{4,23}$. Além disso, pode-se diferenciá-lo do granuloma por apresentar uma imagem radiolúcida de limites precisos e ser rodeado por linha radiopaca de osteogênese reacional ${ }^{11}$.

Muitas lesões podem simular clínica e radiograficamente, o cisto radicular, incluindo-se o ceratocisto odontogênico, o Ameloblastoma e lesões malignas como carcinoma de células claras ${ }^{4}$. Alguns autores incluíram os tumores odontogênicos, as lesões de células gigantes, as doenças metastáticas e os tumores ósseos primários como lesões que, ocasionalmente, podem imitar o cisto radicular na imagem radiográfica, sendo que em qualquer destas condições o dente relacionado possui vitalidade $^{3}$. Outros também incluíram, que o diagnóstico diferencial do cisto radicular deve também contemplar o abscesso, estádio precoce de displasia periapical do cemento, cicatriz periapical radiolúcida, defeito cirúrgico periapical, cisto ósseo traumático e granuloma central de células gigantes, sendo a observação clínica fundamental neste processo $^{8}$.

O epitélio do cisto radicular é do tipo pavimentoso estratificado não-queratinizado, de espessura variável, o revestimento epitelial do cisto radicular. Este revestimento se origina dos restos epiteliais de Malassez presentes no ligamento periodontal ${ }^{3,4,23}$. Em raras ocasiões, o cisto pode exibir-se revestido por epitélio cilíndrico ciliado pseudoestratificado ou do tipo respiratório ${ }^{23}$, ou ainda, epitélio simples composto por células cuboidais associadas às células mucosas tipo caliciformes próprias do trata digestivo ${ }^{4}$.

As escolhas terapêuticas indicadas para os cistos periapicais variam desde $\mathrm{o}$ tratamento endodôntico convencional até o tratamento cirúrgico. A questão a ser ilustrada é a real capacidade de o tratamento endodôntico eliminar um cisto periapical. A diminuição dos cistos radiculares, após a instituição de terapêutica endodôntica convencional, tem sido evidenciada por diversos estudos ${ }^{1,24}$.
De início deve-se ter em mente que a causa das lesões perirradiculares é microbiana, portanto o tratamento deve ser baseado na desinfecção dos canais radiculares. Faz-se necessário, portanto a aplicação de todas as manobras disponíveis para alcançar este alvo, aí incluindo o preparo biomecânico, emprego de substâncias químicas e aplicação de medicação intracanal ${ }^{25}$.

O tratamento indicado, quando há ocorrência de cisto periapical de grandes tamanhos, é a enucleação cirúrgica do mesmo, associado ou não à exodontia do elemento envolvido. Em alguns casos, pode-se recomendar o tratamento endodôntico do dente afetado seguido de apicectomia e enucleação da lesão cística ${ }^{3,23}$.

A enucleação consiste na retirada por completo da lesão cística, sem ruptura da cápsula fibrosa. Esta técnica deve ser realizada com cuidado, pois a remoção da peça por inteiro diminui as chances de recidiva. Sua principal vantagem é permitir o exame histopatológico integral da lesão além de proporcionar o tratamento adequado da lesão ${ }^{11,26}$. É um método pelo qual a lesão cística é movida por inteira sem que ocorra a ruptura. É o tratamento de escolha e deve ser empregada qualquer tipo de cisto dos maxilares que possa ser removido sem sacrificar, desnecessariamente, as estruturas adjacentes ${ }^{23}$.

Após a enucleação, utiliza-se uma broca ou cureta para remover de 1 a $2 \mathrm{~mm}$ de osso ao redor de toda a cavidade cística. Este processo serve para retirada de células epiteliais remanescentes que possam estar presentes na periferia da parede cística ou cavidade óssea. A proliferação dessas células pode causar a recidiva do cisto ${ }^{26}$.

$\mathrm{Na}$ marsupialização é criada uma janela cirúrgica na parede do cisto, esvaziando o conteúdo cístico e conservando a continuidade entre o cisto e a cavidade bucal, seio maxilar ou cavidade nasal. Esta conduta reduz a pressão intracística promovendo uma redução do cisto e resultando em preenchimento ósseo. Sua principal vantagem é de ser um procedimento simples de realizar. A maior desvantagem desta técnica é que o tecido patológico é deixado "in situ", sem ser submetido a um exame histopatológico por completo e ainda existe o inconveniente do paciente precisar conservar o local devidamente higienizado, a fim de evitar infecção $^{26}$

A técnica de marsupialização frequentemente é acompanhada de enucleação em um momento posterior Após a marsupialização, ocorre uma breve cicatrização inicial e, usualmente, há uma redução apreciável do tamanho da cavidade cística permitindo, assim, o método de enucleação secundária, sem a ocorrência de injúria às estruturas adjacentes. Este acesso combinado reduz a morbidade e antecipa a cicatrização completa ${ }^{26,27}$.

A descompressão com posterior enucleação é um método menos agressivo pelo qual uma pequena janela cirúrgica é feita no interior da cavidade cística e é conservada por um cateter ou um tubo, para assegurar constante drenagem e diminuir a pressão intracística. Essa técnica diminui a cavidade e ao atingir um tamanho menor realiza-se a cirurgia, enucleando-se completamente a membrana cística, dessa forma elimina as desvantagens da cirurgia pela enucleação, que pode afetar a vitalidade de dentes adjacentes ou ocasionar danos a nervos ${ }^{28}$. Alguns autores realizaram uma pesquisa com a finalidade de auxiliar o profissional da Odontologia a indicar o tratamento cirúrgico adequado para os cistos de diferentes tipos. De acordo com a pesquisa, o tratamento dos cistos dos maxilares é de natureza excepcionalmente cirúrgica, podendo ser subdividido em três modalidades terapêuticas: 
enucleação, marsupialização e descompressão. Segundo os autores, cada técnica cirúrgica possui a sua exata indicação, cabendo ao especialista analisar perfeitamente o tipo de cisto, sua localização, seu grau de envolvimento com as estruturas adjacentes, ou seja, o tamanho da lesão e ainda as condições gerais do paciente. Para os autores, o sucesso do caso dependerá de um plano de tratamento, além dos conhecimentos da técnica cirúrgica e da anatomia orofacial $^{29}$.

Em relação à mutação carcinomatosa do cisto radicular, são poucos os relatos, mas bem documentados, os quais sugerem que o carcinoma espinocelular pode, ocasionalmente, originar-se a partir do revestimento epitelial do cisto radicular ou de outros cistos odontogênico. É rara a transformação maligna do epitélio do cisto radicular ${ }^{23}$. O material cístico que for movido, cirurgicamente, deve ser submetido a exame histopatológico ${ }^{26}$.

\section{CASO CLÍNICO}

Paciente M.C.C.B., gênero feminino, melanoderma, 28 anos, procedente da cidade de Manacapuru/AM, compareceu ao serviço de Cirurgia e Traumatologia Bucomaxilofacial da Universidade do Estado do Amazonas - UEA (CTBMF- UEA), encaminhada de um Centro de Especialidades Odontológicas - CEO da cidade de Manaus, com queixa álgica e aumento de volume do lado direito da face.

Durante a anamnese, a paciente relatou ter realizado tratamento e posterior retratamento endodôntico do elemento dentário 12 sem resolução clínica do quadro, pois não havia sido observada diminuição aparente da lesão intraóssea, ao avaliar as radiografias intrabucais. Além do mais, a paciente continuava a relatar sensibilidade dolorosa na região. Negou alergias, traumas anteriores ou quaisquer alterações sistêmicas dignas de nota. Ao exame clínico extrabucal, observou-se que a paciente apresentava discreta assimetria facial devido a um apagamento no sulco nasogeniano direito (Figura 1). Durante a palpação foi observada tumefação de consistência firme do lado direito da região geniana. Não foi observado nenhuma cadeia ganglionar que mostrasse sinais de linfadenopatia.
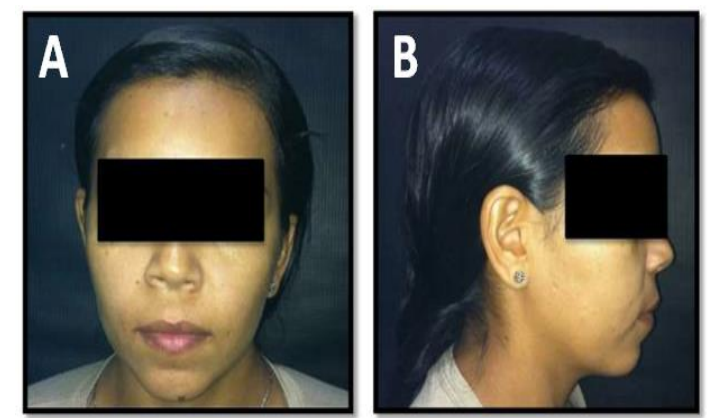

Figura 1: A-Presença de discreta assimetria facial e apagamento do sulco nasogeniano direito, na vista frontal; B-Vista lateral.

Ao exame clínico intrabucal observou-se um discreto abaulamento na região do fundo de sulco vestibular na região correspondente aos elementos dentários 11,12 e 13 , assim como, ausência de alteração da coloração da mucosa, sendo esta semelhante à dos tecidos vizinhos. A palpação constatou-se tumefação de consistência firme e com queixa de dor (Figura 2).

Ao exame de imagem, através de Tomografia Computadorizada de feixe cônico, foi evidenciada uma imagem hipodensa, unilocular, circunscrita por um halo esclerótico e próximo ao ápice dentário dos elementos 11,12 e 13, que exibia ainda proximidade com soalho de fossa nasal e com a parede medial do seio maxilar direito (Figuras 3 e 4).

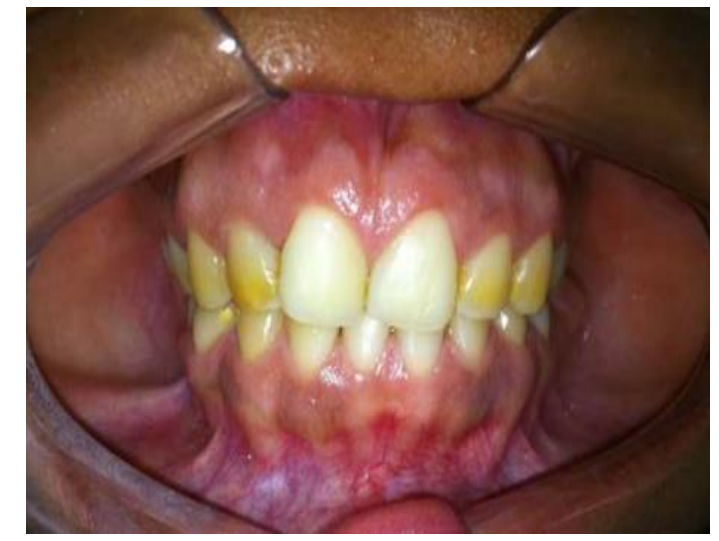

Figura 2: Abaulamento na região de fundo de sulco vestibular, próximo às raízes dos elementos dentais 11,12 e 13 .

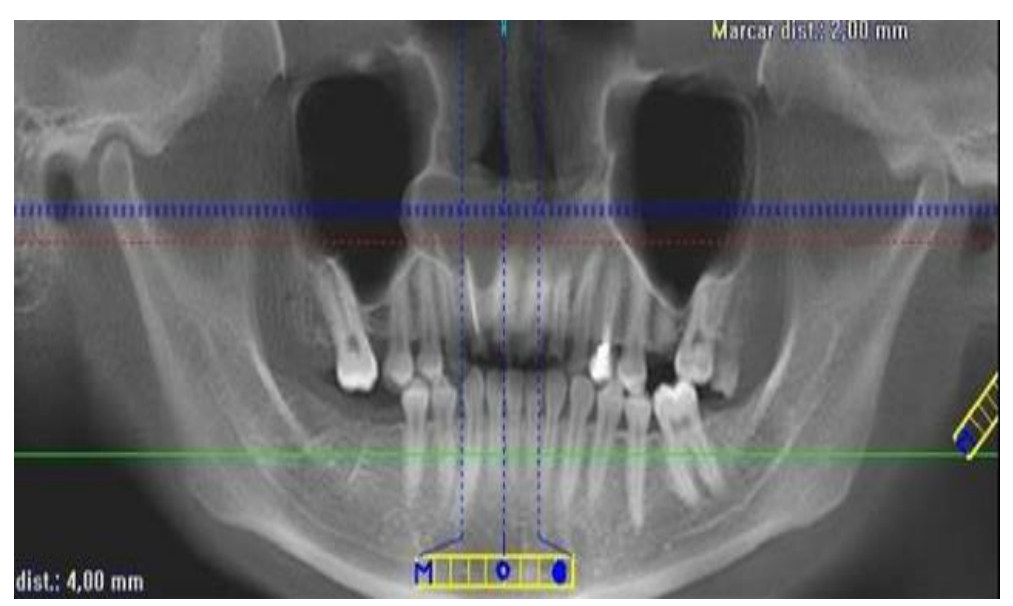

Figura 3: Radiografia Panorâmica obtida da Tomografia inicial, revelando uma imagem hipodensa e circunscrita na região do ápice dos elementos, 11,12 e 13
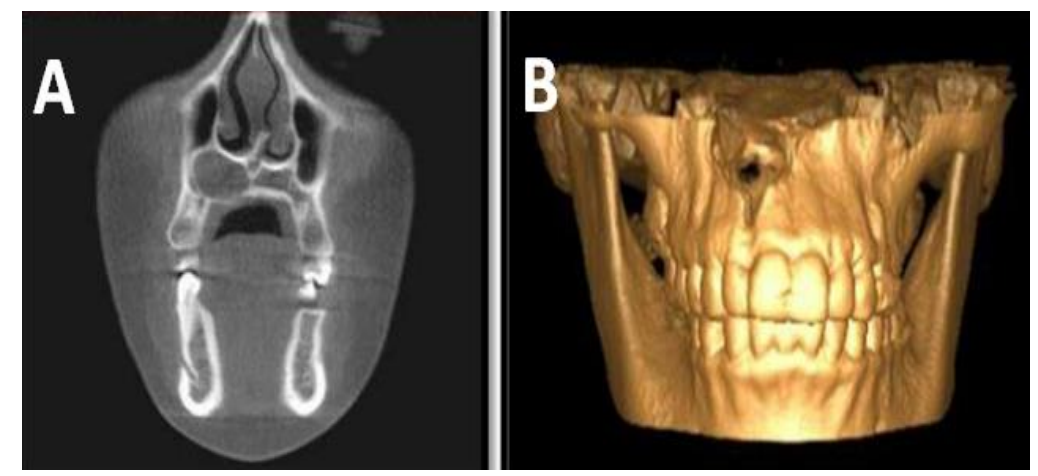

Figura 4: Tomografia computadorizada (TC), A- Corte coronal, exibindo a extensão da lesão que está acometendo a maxila direita; B- Reconstrução 3D a partir da TC.

Diante dos achados clínicos e radiográficos, uma biópsia excisional da lesão foi indicada. Exames préoperatórios, como Hemograma completo, Coagulograma, TP (Tempo de Protrombina), TTPA (Tempo de Tromboplastina Parcial Ativada), Glicemia em jejum, uréia e creatinina, TGO (Transaminase Glutâmico Oxalacética) e TGP (Transaminase Glutâmica Pirúvica), RX de tórax, ECG (Eletrocardiograma) e Risco cirúrgico, foram solicitados para a realização da cirurgia em ambiente hospitalar. Todos eles encontravam-se dentro do padrão de normalidade.

Foi realizada uma punção aspirativa, com uma seringa de $20 \mathrm{ml}$, para verificar a natureza e consistência do conteúdo da lesão intra-óssea. O conteúdo obtido da punção consistia num líquido turvo e de coloração amarelo citrino (Figura 5).

Devido à extensão da lesão e a sua proximidade com assoalho da fossa nasal e a parede medial do seio maxilar, o procedimento cirúrgico foi planejado para ser realizado em ambiente hospitalar, na Fundação Hospital Adriano Jorge FHAJ, sob anestesia geral.

No suporte medicamentoso pré-operatório, a paciente foi submetida a uma dose profilática de Cefalotina (1g) e de Dexametasona $(8 \mathrm{mg})$, objetivando prevenir qualquer tipo de infecção e minimizar a formação excessiva de edema pósoperatórios, advindos da manipulação cruenta dos tecidos locais. 
Procedeu-se então uma incisão intrabucal na região, utilizando-se o retalho de Newman modificado. Após o rebatimento do retalho de extensão total mucoperiostal, notou-se o abaulamento evidente na região vestibular da maxila (Figura 6) e seguiu-se então com a osteotomia da tábua óssea vestibular, com a utilização da fresa cirúrgica ${ }^{\circ}$ 08, sob irrigação constante com soro fisiológico, no intuito de criar uma janela óssea para posterior enucleação da lesão.

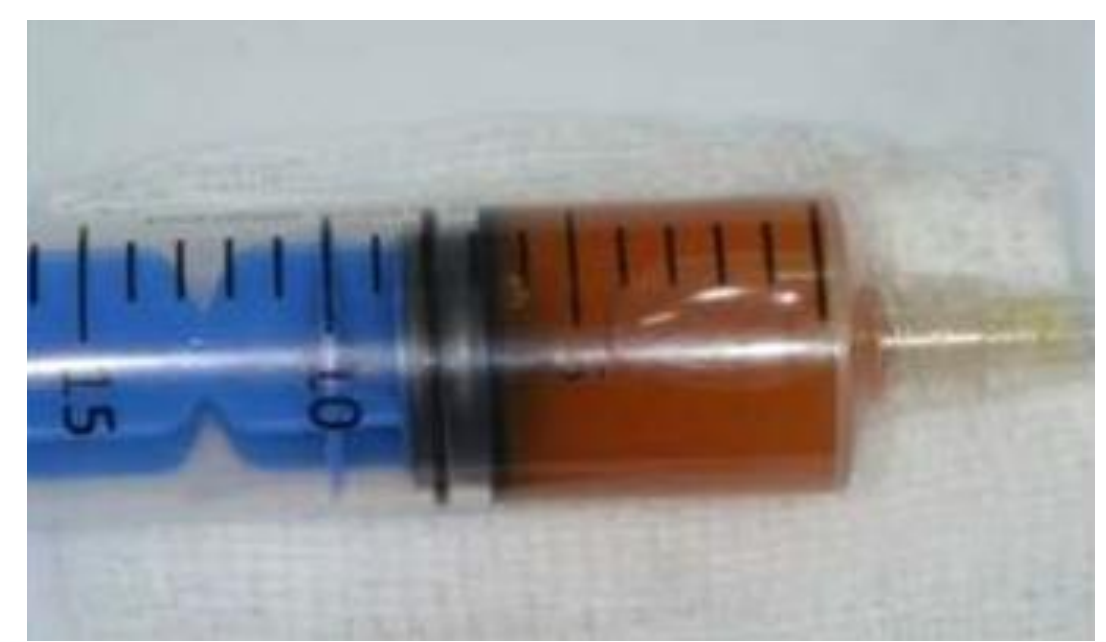

Figura 5: Fotografia mostrando o material aspirado da lesão.

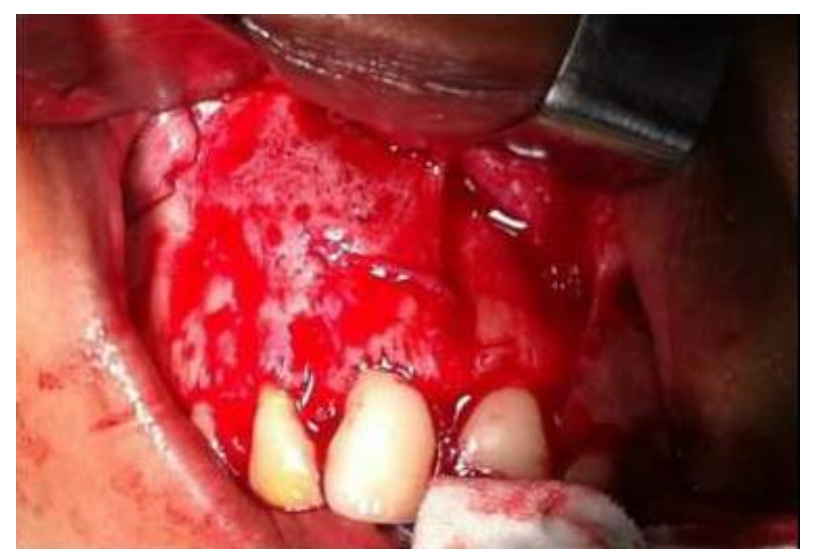

Figura 6: Retalho mucoperiosteal para acesso à lesão.

Deste modo, foi realizada a enucleação da lesão e curetagem da loja óssea, com auxílio da cureta de Lucas. Removeu-se a mesma sem ruptura da cápsula que a envolvia, obtendo um espécime de aproximadamente $25 \mathrm{~mm}$ em seu maior diâmetro (Figura 7,8 e 9).

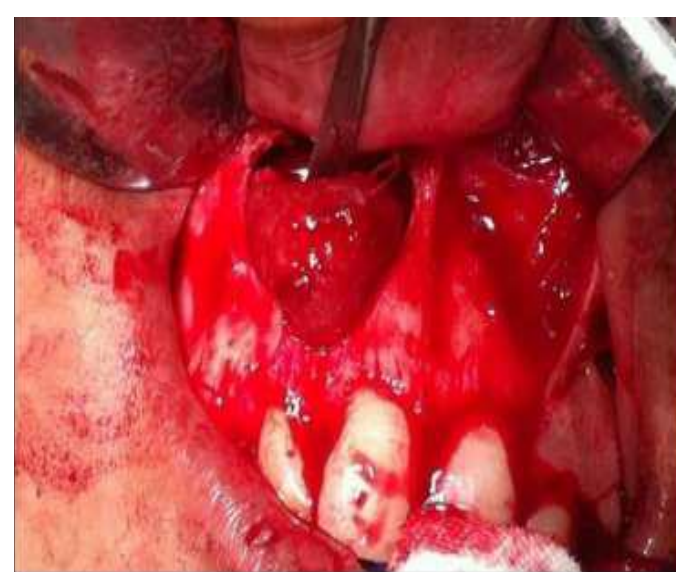

Figura 7: Aspecto transcirúrgico da lesão após a elevação do retalho e osteotomia. Uma cureta é usada para destacar a lesão das paredes ósseas.

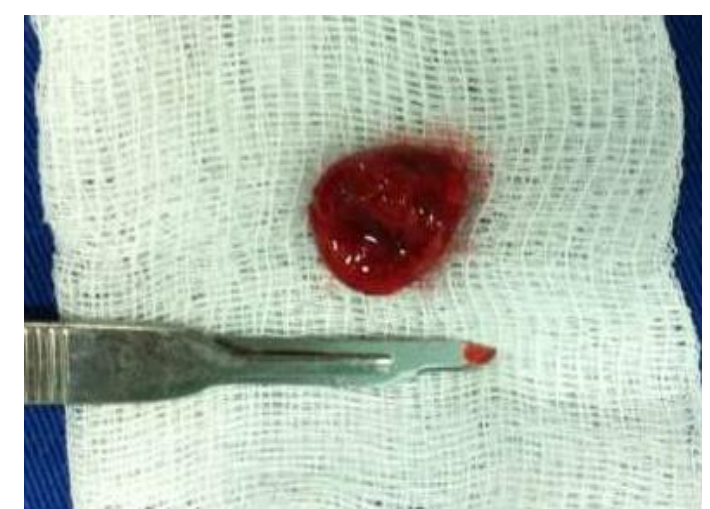

Figura 8: Fragmento de tecido mole, de consistência firme, de forma e superfície irregular e cor acinzentada, medindo 2,0x 1,6x 0,4 cm, após exérese.

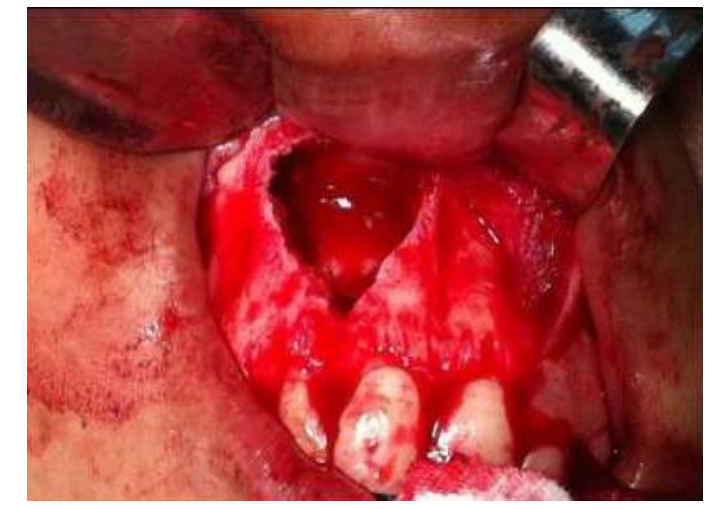

Figura 9: Loja cirúrgica após a enucleação da lesão. Nota-se que o teto da loja está integro, não havendo assim prejuízo para o seio maxilar e a fossa nasal.

Subsequentemente, o retalho mucoperiosteal foi reposicionado e suturado através de pontos interpapilares e pontos simples nas incisões oblíquas relaxantes, com fio de sutura vicryl 4-0 (Figura 10). O procedimento cirúrgico transcorreu sem intercorrências.

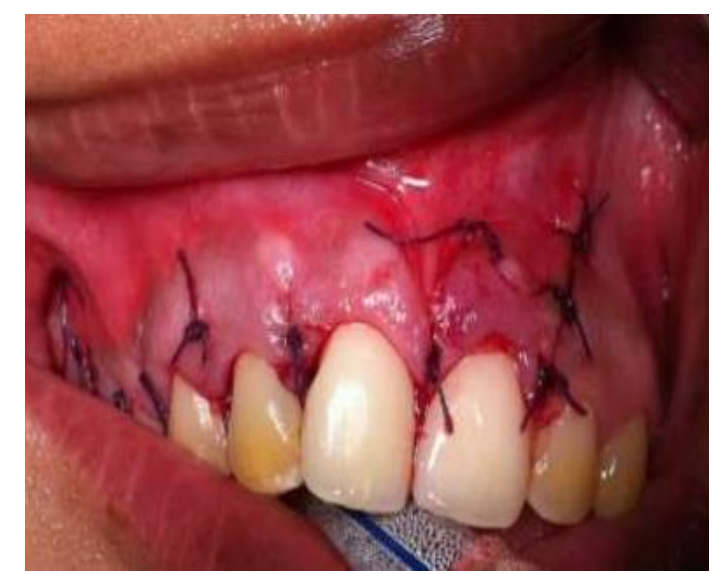

Figura 10: Síntese do retalho mucoperiostal, proporcionando o fechamento por primeira intenção da ferida cirúrgica.

No primeiro dia pós-operatório a paciente iniciou dieta líquido-pastosa via oral, recebendo alta hospitalar após um dia de internação. Foi instituída a administração de Cefalotina $1 \mathrm{~g}$ (de seis em seis horas) e Tenoxicam 20mg (de doze em doze horas), ambos por via endovenosa no primeiro dia pós-operatório.

Após a alta hospitalar, a paciente foi orientada sobre a importância de sua cooperação e adesão para o sucesso do tratamento proposto. Também foi esclarecida quanto aos cuidados pós-operatórios, que dizem respeito à higiene bucal, repouso e alimentação. A medicação pós-operatória prescrita foi Amoxicilina $500 \mathrm{mg}$, de oito em oito horas (durante 3 dias), Nimesulida $100 \mathrm{mg}$, de doze em doze horas (por 3 dias), e Dipirona sódica $500 \mathrm{mg}$ de seis em seis horas (por 1 dia). A paciente foi orientada a não escovar a área cirúrgica, mas que fosse realizado um enxágue bucal duas vezes ao dia com Periogard® $(0,12 \%)$ e que permanecesse em dieta líquido pastosa.

Após 7 dias decorridos do procedimento cirúrgico, a paciente retornou à Policlínica Odontológica da Universidade do Estado do Amazonas - UEA para remoção da sutura (Figura 11).

O espécime cirúrgico foi acondicionada em um frasco contendo formol a $10 \%$, previamente identificado, e encaminhado posteriormente para uma análise histopatológica no laboratório de patologia da Universidade do Estado do Amazonas - UEA. Na macroscopia da peça cirúrgica, que em seu maior diâmetro possuía $25 \mathrm{~mm}$, foi observado fragmento de tecido mole, de consistência firme, de forma e superfície irregular e cor acinzentada, medindo 2,0x 1,6x $0,4 \mathrm{~cm}$.

Os cortes histológicos revelaram fragmento de cápsula cística exibindo lume virtual, preenchido por restos 
hemorrágicos e debris celulares e revestido por epitélio estratificado pavimentoso não queratinizado, formando projeções arciformes para o interior da cápsula, associado à degeneração hidrópica, espongiose e exocitose leucocitária. A cápsula exibia tecido conjuntivo denso não modelado, permeada por intenso infiltrado inflamatório mononuclear rico em plasmócitos e mostrando focalmente cristais de colesterol associados à reação de corpo estranho com formação de células gigantes multinucleadas. Completando o quadro, havia presença de hemorragia na cápsula. O diagnóstico definitivo foi de Cisto periapical (Figura 12).

Aos 4 meses pós-operatório, foi realizado uma nova radiografia panorâmica onde observou-se a diminuição significativa da lesão com neoformação óssea (Figura 13).

A paciente permaneceu sob acompanhamento e uma nova radiografia panorâmica foi obtida após 12 meses decorridos da cirurgia. Neste exame, foi possível observar radiopacidade sugestiva de neoformação óssea no local (Figura 14). Após 18 meses foi solicitado um novo exame tomográfico, no qual se observou diminuição da lesão e consequente neoformação óssea local (Figura 15 e 16).

No exame clínico intrabucal, os tecidos bucais encontravam-se dentro do padrão de normalidade, não mostrando sinais de recidiva (Figura 17 e 18).

A paciente permanece sob acompanhamento clínico e radiográfico, sem queixa álgica ou qualquer outro tipo de queixa.

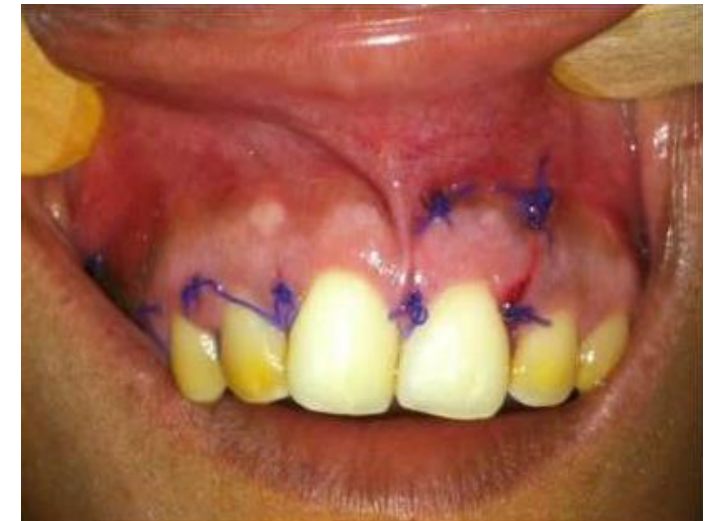

Figura 11: Fotografia mostrando o pós-operatório de 7 dias, durante a remoção de sutura.

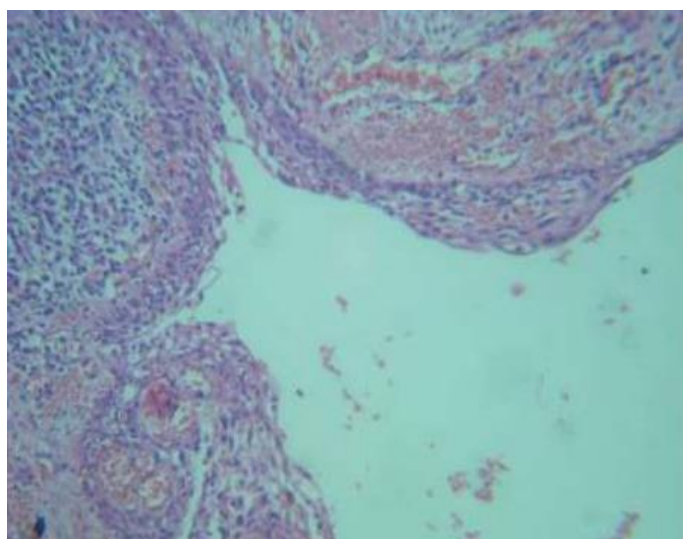

Figura 12: Fotografia da lâmina histológica mostrando o diagnóstico final de cisto periapical.

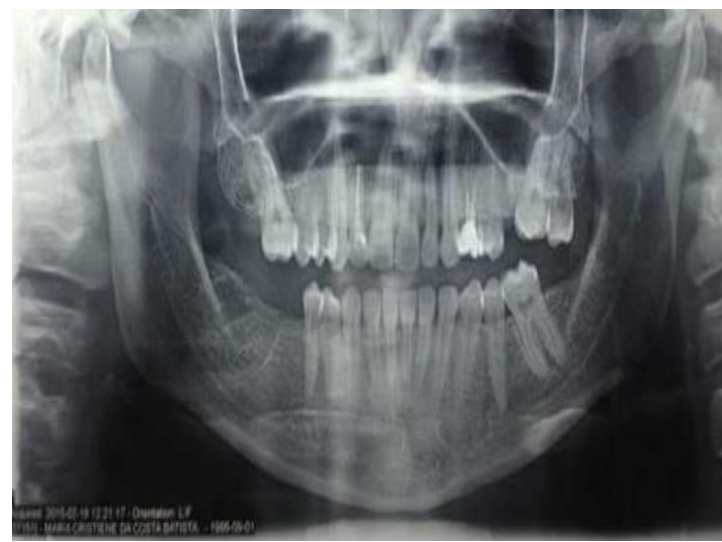

Figura 13: Radiografia panorâmica de 4 meses pós-operatório

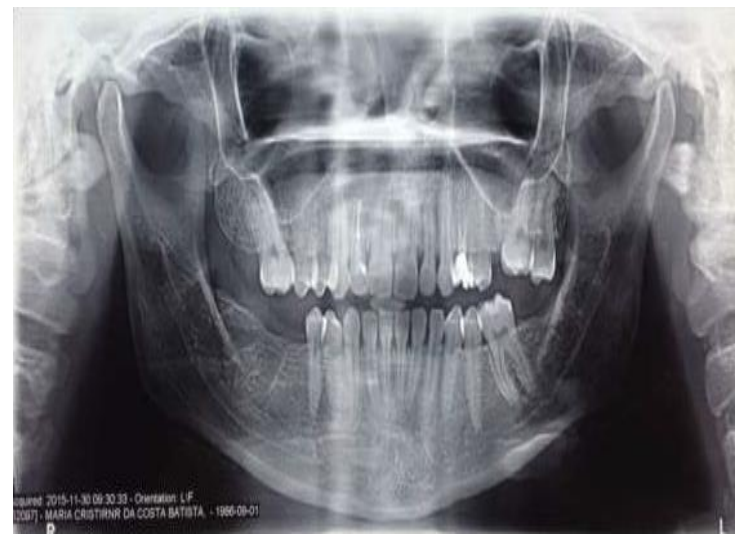

Figura 14: Radiografia panorâmica (controle de 12 meses). Observe o desaparecimento quase total da radiolucidez e imagem sugestiva de neoformação óssea próximo ao ápice dentário dos elementos 11,12 e 13.

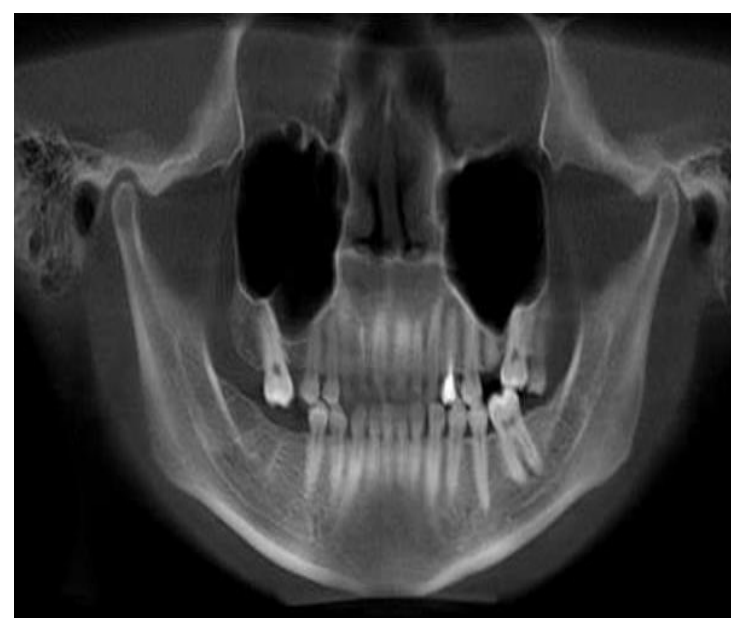

Figura 15: Imagem Panorâmica, obtida a partir da tomografia computadorizada de 18 meses pós-operatório.
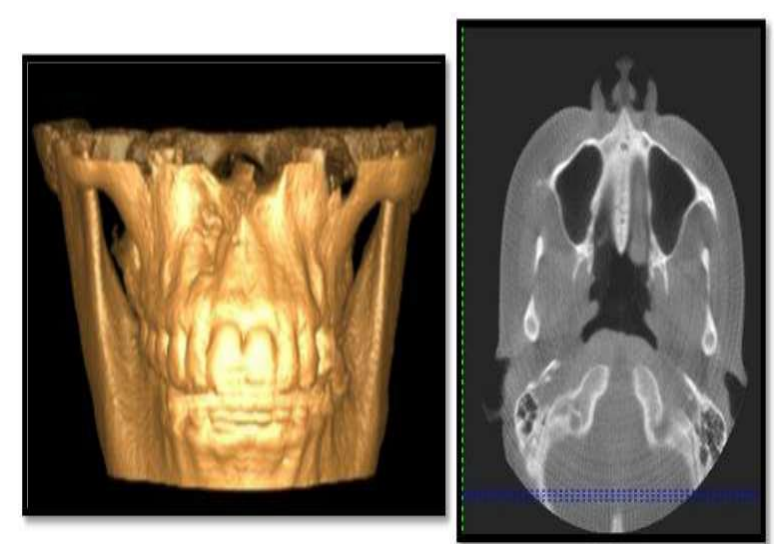

Figura 16: A- Reconstrução 3D a partir da Tomografia computadorizada; B-Corte axial obtido da TC.

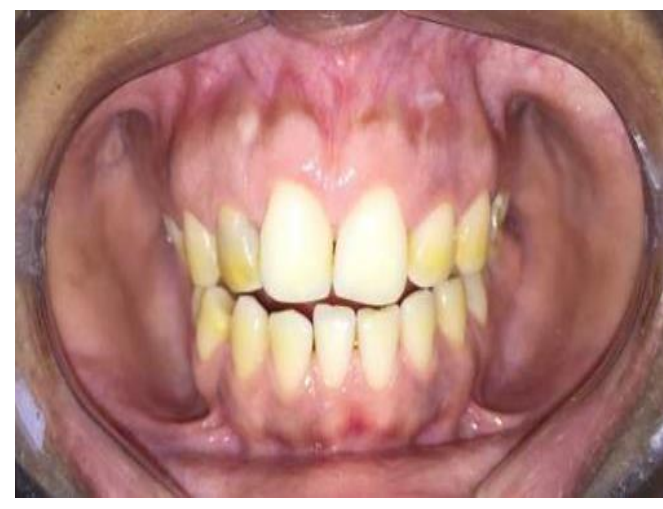

Figura 17: Fotografia intrabucal frontal, após 18 meses pós-operatório.

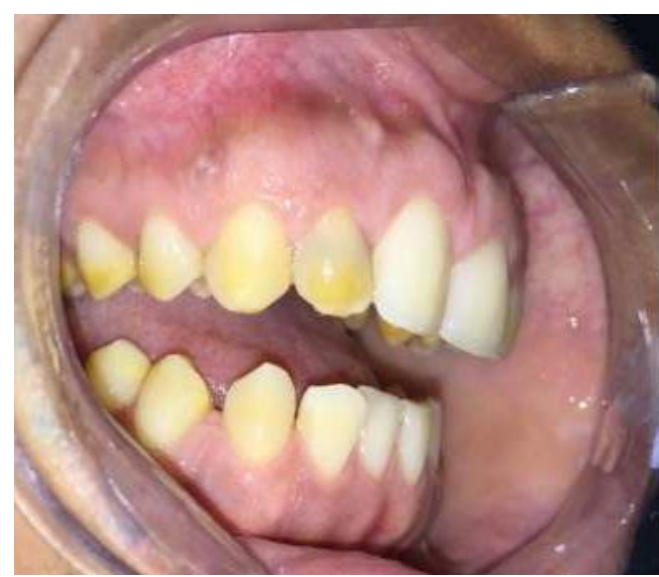

Figura 18: Fotografia intrabucal lateral direita, após 18 meses pós operatórios. 


\section{DISCUSSÃO}

Relatamos aqui um caso de um cisto radicular que estava envolvendo a região anterior de maxila direita. $\mathrm{Na}$ maioria dos casos, todos os cistos odontogênicos, frequentemente, caracterizam-se por lesões assintomáticas em sua fase inicial, porém quando associada à infecção bacteriana secundária, causa grande deformidade óssea, dor espontânea e rápido aumento de volume da cavidade cística $^{2,24}$, tal como ocorreu na lesão do caso descrito.

O cisto radicular é a entidade patológica de origem inflamatória mais comum dos cistos odontogênicos representando de 40 a $85 \%$ de todas as lesões apicais e o segundo mais comum cisto odontogênico na população pediátrica ${ }^{19,21,25}$. Porém alguns autores apontam em seu estudo uma prevalência maior de cisto dentígero ${ }^{18}$. Outro estudo mostrou não ter diferença de prevalência entre Caucasianos e descendentes africanos em 507 casos analisados no Brasil ${ }^{30}$.

Alguns autores relatam que esta lesão acomete preferencialmente adultos entre a terceira e a sexta décadas de vida ${ }^{3}$. Outro autor ressalta que a terceira década de vida apresenta uma prevalência considerável ${ }^{6}$. Destaca-se ainda baixa prevalência da lesão durante a primeira década de vida, constituindo-se num fato interessante, visto que a cárie dentária e dentes sem vitalidade são bem frequentes neste grupo etário e, apesar disto, os cistos radiculares não são comumente associados aos dentes decíduos ${ }^{3,6,23}$. A paciente do presente trabalho, na ocasião da abordagem clínica e cirúrgica, encontrava-se com 28 anos, ou seja, na segunda década de vida, destoando do que a literatura nos apresenta para a ocorrência do cisto radicular.

A maioria dos cistos radiculares é assintomática, mas pode haver dor ou sensibilidade se ocorrer exacerbação aguda. Nas lesões extensas, quando ocorrem, podem ser observadas tumefação, mobilidade e deslocamento dentário $^{8,18}$.

O cisto radicular localiza-se no ápice de qualquer dente desvitalizado, sendo a maioria encontrada na maxila, particularmente na região anterior, seguida pela região maxilar posterior, região posterior da mandíbula e região anterior da mandíbula ${ }^{3}$. Nos cistos de longa evolução clínica pode ser observada a reabsorção radicular do dente envolvido e, usualmente, o afastamento e a reabsorção das raízes dos dentes vizinhos ${ }^{11,28}$.

Segundo uma dada casuística, $60 \%$ dos cistos radiculares foram encontrados na maxila e $40 \%$ na mandíbula ${ }^{6}$. Assim, em apenas um dos dois pontos supracitados, o caso em questão concordou com o que já é consagrado pela literatura. Ou seja, no relato, a paciente apresentava sintomatologia dolorosa, relacionada à área do cisto, o que nos leva a pensar na ideia de infecção secundária local. E a localização do cisto foi na região anterior da maxila direita, concordando com os achados literários.

$\mathrm{O}$ cisto radicular apresenta uma imagem radiolúcida de densidade homogênea, unilocular, circunscrita, arredondada ou ovalada, associada a um ápice radicular intacto, de um dente desvitalizado, com o rompimento da lâmina dura ao nível do ápice ${ }^{11}$.

Quando o cisto radicular apresentar-se como uma lesão de pequenas dimensões seu diagnóstico diferencial em relação ao granuloma periapical pode ser bastante difícil ${ }^{20}$. Já segundo outros autores, radiograficamente não é possível diferenciar o cisto radicular do granuloma periapical ${ }^{3}$.

A grande maioria dos autores é unânime em afirmar que os cistos dos maxilares podem ser tratados cirurgicamente através de uma das seguintes técnicas básicas: enucleação, marsupialização, combinação em etapas dos dois procedimentos ou enucleação com
curetagem $^{3,6,8,19,26}$.

Caso o cisto radicular não seja submetido a tratamento, a lesão aumentará lentamente de tamanho, às custas de osso circunjacente. O osso sofre reabsorção, porém, raramente ocorre uma expansão compensatória das tábuas corticais, como se observa no caso do cisto dentígero ${ }^{23}$.

No caso em questão, a lesão apresentava histórico de evolução de 1 ano, após tratamento e retratamento endodôntico do elemento dental 12, não mostrando nenhuma evidência de resolução clínica, pois não havia sido observado diminuição aparente da lesão intraóssea, através do acompanhamento radiográfico. Assim, segundo a literatura, se a terapia endodôntica for bem conduzida, o granuloma deverá ser reparado, já o cisto verdadeiro precisará ser removido cirurgicamente, pois dificilmente sofrerá reparo somente com a terapia endodôntica ${ }^{4}$.

Alguns autores citam que lesões extensas em dentes restauráveis têm sido tratadas, com sucesso, por meio do tratamento endodôntico conservador quando acompanhado de biópsia e marsupialização, descompressão ou fenestração ${ }^{8}$. Outros autores corroboram que simples acessos, tais como a marsupialização ou a colocação de um tubo para descompressão, podem ser alternativas para lesões císticas extensas ${ }^{25}$.

Alguns trabalhos relatam que a técnica da descompressão cística com a utilização de um dreno na região bucomaxilomaxial, mostrou-se satisfatório e eficaz como método auxiliar de tratamento. Este procedimento simples e rápido promove uma significativa redução da lesão, provoca mínimos danos às estruturas anatômicas e evita uma cirurgia extensiva durante a enucleação, facilitando, portanto, o mecanismo de reparo ósseo e/ou cicatrização fibrosa ${ }^{24}$.

Por via de regra, lesões císticas menores são tratadas pela enucleação cirúrgica da lesão. No entanto, lesões císticas maiores podem ser abordadas através da técnica cirúrgica de marsupialização com posterior enucleação, diante da regressão do tamanho do cisto ${ }^{3,6,8,19,26}$. No presente caso, a lesão apresentava dimensões relativamente extensas e em íntimo contato com estruturas anatômicas nobres dos maxilares, como o seio maxilar e a fossa nasal. Assim, seguindo estes conceitos, a opção terapêutica para o presente caso poderia ser a marsupialização da lesão e acompanhamento da lesão até se chegar a um tamanho compatível com a dimensão para a realização da enucleação cirúrgica do cisto, sendo tudo isso realizado em ambiente ambulatorial. Porém, diante da condição socioeconômica da paciente, por residir no interior do estado do Amazonas, distante da capital Manaus, e por não ser colaborativa para consultas acompanhamento da área marsupializada, o tratamento proposto foi o de enucleação total da lesão em ambiente hospitalar, sob anestesia geral. Tratamento este bem indicado, embasado na literatura, realizado com sucesso e com excelente recuperação pós-operatória do paciente.

\section{CONCLUSÃO}

O presente trabalho abordou o tratamento cirúrgico de um cisto radicular, uma das mais destacadas lesões no âmbito da Patologia Bucal e da Estomatologia. Estes cistos, apesar de relativamente comuns, podem atingir grandes proporções devido à falta de sintomatologia na maioria dos casos. Desta forma, torna-se importante a inclusão do exame radiográfico na rotina odontológica, para que estas lesões possam ser diagnosticadas e tratadas de forma adequada. $\mathrm{O}$ 
sucesso no tratamento dos cistos radiculares depende de um correto planejamento do caso, além dos conhecimentos da técnica cirúrgica e da anatomia bucomaxilofacial.

\section{REFERÊNCIAS}

1. Nair PNR, Pajarola G, Schroeder HE. Types and incidence of human periapical lesions obtained with extracted teeth. Oral Surg Oral Med Oral Pathol Oral Radiol Endod. 1996; 81(1):93-102.

2. Sauaia TS, Pinheiro ET, Imura N. Cistos PeriRadiculares Uma Proposta de Tratamento. RGO. 2000; 48(3):130-4.

3. Regezi JA, Sciubba JJ. Patologia oral: correlações clinicopatológicas. 3.ed. Rio de Janeiro: Guanabara Koogan, 2000; p.260-2.

4. Leonardo MR, Leal JM. Endodontia: tratamento de canais radiculares. São Paulo: Editorial Médica Panamericana. 1998; p.94-100.

5. Bhaskar SN. Nonsurgical resolution of Radicular Cysts. Oral Surg Oral Med Oral Pathol. 1972; 34(3):458-68.

6. Shear M. Cistos da região bucomaxilofacial. São Paulo: Santos. 1999; p.94-100.

7. Mass E, Kalpan F, Hishberg K. A clinical and histopathological study of radicular cysts associated with primary molars. J Oral Pathol Med. 1995; 24(10):458-61.

8. Neville BW, Damm DD, Allen CM, Bouquot JE. Patologia oral \& maxilofacial. 3. ed., Rio de Janeiro: Guanabara Koogn; 2009.

9. Martins-Filho PRS, Brasileiro BF, Piva MR, Silva LCF, Reinheimer DM, Marzola C. Cisto radicular na maxila relato de caso clínico cirúrgico. Rev ATO. 2009; 4(10):881-9.

10. Lin LM, Huang GT, Rosenberg PA. Proliferation of epithelial cell rests, formation of apical cysts, and regression of apical cysts after periapical wound healing. JOE. 2007; 33(8): 908-16.

11. Freitas A de, Rosa JE, Sousa IF. Radiologia odontológica. São Paulo: Artes Médicas; 2000; p.38691; 431-33; 468-9.

12. Kramer IRH, Pindborg JJ, Shear M. Histological typing of odontogenic tumours. WHO (International histological classification of tumors). Berlim: SpringerVerlag; 1992; p.34-42.

13. Cohen S, Hargreaves KM. Caminhos da polpa. 9 ed. Rio de Janeiro: Elsevier; 2007.

14. Benn A, Altini M. Dentigerous cysts of inflammatory origin: a clinicopathologic study. Oral Surg Oral Med Oral Pathol Oral Radiol Endod. 1996; 81(2):203-9.

15. Mosqueda-Taylor A, Yrigoyen-Camacho ME, DiazFranco MA, Torres-Tejero MA. Odontogenic cysts. Analysis of 856 cases. Med Oral. 2002; 7(2):89-96.

16. Koseoglu BG, Atalay B, Erdem MA. Odontogenic cysts: a clinical study of 90 cases. J Oral Sciense. 2004; 46(4):253-7.

17. Grossmann SM, Machado VC, Xavier GM, Moura MD, Gomez RS, Aguiar MC et al. Demographic profile of odontogenic and selected nonodontogenic cysts in a Brazilian population. Oral Surg Oral Pathol Oral Radiol Endod. 2007; 104(6):e35-41.

18. Souza ME, Torres MA, Duarte AHS, Sobral ANV. Lesões periapicais: estudo epidemiológico. Rev Bras Patol Oral. 2003; 2(1):30-4.

19. Marzola C. Fundamentos de cirurgia maxilo facial. São Paulo: Big Forms; 2008.
20. Gibson GM, Pandolfi PJ, Luzader JO. Case report: a large radicular cyst involving the entire maxillary sinus. General Dentistry. 2002; 50(1):80-1.

21. Tortorici S, Amodio E, Massenti MF, Buzzanca ML, Burruano F, Vitale F. Prevalence and distribution of odontogenic cyst in Sicily: 1986- 2005. J Oral Sci. 2008; 50(1):15-8.

22. Lopes HP, Siqueira Jr JF. Biologia e técnica. 3 ed. Rio de Janeiro: Guanabara Koogan; 2010.

23. Shafer WG, Hine MK, Levy BM, Tratado de patologia bucal. 4 ed. Rio de Janeiro: Guanabara Koogan; 1987. p.239-47, 455-60.

24. Vasconcelos RG, Queiroz LMG, Alves Júnior LC, Germano AR, Vasconcelos MG. Abordagem Terapêutica em cisto radicular de grandes proporções relato de caso. R bras ci Saúde. 2012; 16(3): 467-74.

25. Schwengber MMB, Hennigen TW, Ponzoni D, Puricelli E. Estudo radiográfico da prevalência de lesões periapicais nas arcadas dentárias. Revista ABO Nacional, 2008;16:214-7.

26. Peterson LJ, Ellis E, Hupp JR, Tucker MR. Cirurgia oral e maxilofacial comtemporânea, 4 ed, Rio de Janeiro: Elsevier; 2005.

27. Lindhe J, Karring T, Lang NP. Tratado de Periodontia Clínica e Implantologia Oral. 3 ed, Rio de Janeiro: Guanabara Koogan; 1999; p.263-6.

28. Araújo A, Gabrielli MFR, Medeiros PJ. Aspectos atuais da cirurgia e traumatologia bucomaxilofacial. São Paulo: Livraria Santos; 2007.

29. Silva FM, Baroni EJ, Cabral RJB. Abordagem do tratamento de lesões cística. Rev Odontol Araçatuba. $2002 ; 23(1): 33-7$.

\section{CONFLITO DE INTERESSES}

Os autores declaram não haver conflitos de interesse.

\section{AUTOR PARA CORRESPONDÊNCIA}

\section{Dannilo Wiklymber Roldao Mendonça}

dannilo.wiklymber@hotmail.com

Submetido em 06/06/2017 Aceito em 08/07/2017 